\title{
Pathotypes and serogroups of enterotoxigenic Escherichia coli isolated from pre-weaning pigs in north Vietnam
}

\author{
Thuy N. Do, ${ }^{1,2}$ Phu H. Cu, ${ }^{2}$ Huyen X. Nguyen, ${ }^{2}$ Tuan X. Au, ${ }^{2}$ Quy N. Vu, ${ }^{2}$ \\ Steve J. Driesen, ${ }^{3}$ Kirsty M. Townsend, ${ }^{1}$ James J.-C. Chin $^{4}$ \\ and Darren J. Trott ${ }^{1}$ \\ ${ }^{1}$ School of Veterinary Science, The University of Queensland, OLD 4072, Australia \\ ${ }^{2}$ National Institute of Veterinary Research, Hanoi, Vietnam \\ ${ }^{3}$ National Escherichia coli Reference and Serotyping Laboratory, Department of Primary \\ Industries, Epsom, VIC 3551, Australia \\ ${ }^{4}$ Immunology \& Microbiology, Elizabeth Macarthur Agricultural Institute, New South Wales \\ Department of Primary Industries, Menangle, NSW 2568, Australia
}

Correspondence

Darren J. Trott

d.trott@uq.edu.au

Received 16 July 2005

Accepted 30 August 2005

\section{INTRODUCTION}

Vietnam is a developing country with a rapidly expanding commercial pig industry. Whilst the majority of production still relies heavily upon smallholding farmers raising small numbers ( $<20$ sows) of indigenous breeds, the number of large-scale intensive piggeries ( $>100$ sows) utilizing imported or cross-bred stock has increased rapidly over the last 10 years (Hoang, 2003). Increased intensification of the industry has resulted in a substantial rise in health-related problems. Whilst respiratory and enteric diseases in growing pigs are recognized, pre-weaning diarrhoea is also a significant problem (Cu et al., 1999; Nguyen, 1995; Trinh, 1980).

Abbreviations: CP, commercial piggery; ETEC, enterotoxigenic Escherichia coli; ND, neonatal diarrhoea; NIVR, National Institute of Veterinary Research; VP, village pig.
In other major pig-producing countries, enterotoxigenic Escherichia coli (ETEC) is the most significant pathogen during the suckling period. Two syndromes are usually recognized: neonatal diarrhoea (ND) in the first 4-5 days of life and scours at 2-3 weeks of age (Bertschinger \& Fairbrother, 1999; Fairbrother, 1999a). In suckling pigs, ETEC strains attach to the intestinal epithelium through the action of F4, F5, F6 or F41 fimbrial adhesins and liberate heat-stable (STa, STb) and/or heat-labile (LT) enterotoxins, causing hypersecretory diarrhoea (Nagy \& Fekete, 1999; Nataro \& Kaper, 1998). ND caused by ETEC is usually controlled by vaccination of the sow in the weeks preceding parturition to ensure that protective maternal antibodies are transferred to newborn pigs through the colostrum. In large commercial piggeries (CPs) in Vietnam, reports of vaccination failure are widespread using both a locally produced killed whole-cell vaccine containing F4 antigen and an 
imported vaccine incorporating F4, F5, F6 and F41 antigens. Furthermore, smallholder farmers in Vietnam and some of the larger CPs do not routinely practice prophylactic vaccination of sows for the control of ETEC (Phu H. Cu, personal communication).

As far as we are aware, there have been no previously published studies conducted in Vietnam to determine the significance of ETEC as a cause of pre-weaning diarrhoea. In addition, very little information is available on which ETEC pathotypes and serogroups are currently present in Vietnamese piggeries. Diagnosis of $E$. coli as causative agents of diarrhoea in Vietnam has mainly been based on clinical signs, the age of affected pigs and the isolation of a pure, heavy growth of E. coli from faecal specimens submitted to a veterinary diagnostic laboratory. PCR amplification of ETEC fimbriae and enterotoxin virulence genes is now used routinely for ETEC identification in other pig-producing countries (Blanco et al., 1997; Ngeleka et al., 2003; Ojeniyi et al., 1994; Osek et al., 1999). These methods are not currently used in veterinary diagnostic laboratories in Vietnam.

The present study was conducted to provide baseline information on the significance of specific ETEC serogroups and pathotypes associated with pre-weaning diarrhoea in piglets in north Vietnam. The major objectives were to determine the significance of ETEC as a cause of preweaning diarrhoea in five selected large CPs, identify the major ETEC serogroups and pathotypes present in the CPs and compare them to a collection of ETEC isolates obtained from VPs raised by smallholding farmers.

\section{METHODS}

Participating commercial piggeries. For this study, it was not possible to randomly select participant piggeries due to the diversity of management and husbandry practices existing within north Vietnam. One piggery was instead chosen from each of the five provinces covering the Red River Delta, the midlands and coastal areas according to the following selection criteria: (i) the piggery had a recognized scouring problem in pre-weaning piglets and was not using vaccines for the control of ETEC; (ii) the mean number of sows was $\geqslant 100$; (iii) the piggery was close enough to the National Institute of Veterinary Research (NIVR), in Hanoi, so that specimens could be processed on the day of collection; and (iv) the piggery's owner and staff were willing to participate in the study.

Case definitions and data management. A template for data recording was designed and introduced to the staff of each piggery. The following data were recorded for each sow farrowing between January and June 2001: sow parity, number of liveborn piglets, age of each piglet when diarrhoea was first observed and the number of piglets with diarrhoea in the litter. Data were recorded for each sow until the piglets were weaned at 21 days of age. A case of diarrhoea was recorded if a suckling piglet was observed to pass liquid, watery faeces and showed signs of dehydration between birth and weaning. A litter was recorded as being affected by diarrhoea when more than $25 \%$ of piglets in the litter were scouring.

Specimen collection, transport and storage. Faecal specimens were only obtained from piglets with diarrhoea. Only one specimen was obtained for bacteriological investigation from a single representative piglet from each litter with diarrhoea. All specimens were obtained within $24 \mathrm{~h}$ of the onset of illness and before any antimicrobial treatment had begun to ensure optimum recovery of $E$. coli. All specimens were processed on the day of collection. In some cases, specimens were obtained following post-mortem examination of moribund animals during monthly farm visits. In these cases, a sample of the intestinal contents from the ileum was collected for bacteriological examination.

Bacteriology. Specimens were plated in parallel onto sheep blood agar (SBA) and MacConkey agar (MCA). The plates were incubated aerobically overnight at $37^{\circ} \mathrm{C}$ and then examined for the presence of bacterial colonies. The presence or absence of haemolytic activity surrounding the colonies growing on SBA was also noted. Isolates of E. coli (originating from a single representative colony on the SBA plate) were considered to be significant only if heavy, pure or nearly pure growth was observed on both SBA and MCA plates. Isolates obtained from the five CPs during the 6 month study were compared with a collection of 62 isolates obtained from VP sources in north Vietnam held at the NIVR. All isolates were confirmed to be E. coli using standard biochemical procedures (indole, methyl red, Voges-Proskauer and citrate utilization tests). After isolation, the bacteria were stored in serum agar stabs at room temperature or in brain heart infusion broth containing $20 \%$ glycerol at $-70{ }^{\circ} \mathrm{C}$. Isolates were not subcultured more than twice before being examined by PCR for the presence of ETEC virulence genes. An E. coli isolate was classified as a strain of ETEC if it carried any of the three enterotoxin virulence genes detected by PCR assay.

PCR for determination of ETEC virulence genes. E. coli reference strains (Do et al., 2005; Osek, 1999) were used as positive controls for each virulence factor detected by multiplex PCR, and a non-pathogenic commensal $E$. coli strain was used as a negative control. Strains 1500 (F6), 1547 (O9:F5), 1520 (O101:F41), 214/O81 (O139:K12:H1, F18) and C600 (K-12) were kindly provided by Dr Jacek Osek, National Veterinary Research Institute (PIWet), Poland. Strains FV847a (O149:F4, LT STa STb) and FV2586 (O157:F4, LT $\mathrm{STb})$ were kindly provided by Professor Dr Jorge Blanco Alvarez (Laboratorio de Refrencia de E. coli, Spain). Strain 1078/01 (0149: K91:F4) was provided by the National E. coli Reference and Serotyping Laboratory, Department of Primary Industries, Epsom, Victoria.

PCR for the identification of fimbrial (F4, F5, F6, F41 and F18) and enterotoxin (STa, STb and LT) genes was carried out as previously described (Do et al., 2005). A negative control (all reagents except template DNA) and positive control (bacterial DNA from the reference strains) were included for each PCR. All PCR reactions were performed in duplicate.

Serology. A subset of 170 E. coli isolates was serogrouped at the National E. coli Reference Laboratory, Department of Primary Industries, Epsom, Victoria, Australia. Slide agglutination tests were performed using a set of $\mathrm{O}$ and $\mathrm{OK}$ rabbit antisera representing the most common porcine E. coli serogroups (O8, O8G7, O9, O20, O64, O101, O138:K81, O139, O139:K82, O141:K85ac, O141:K85ab, O147:K89, O149:K91 and O157:K17) as well as four F-antisera (F4, F5, F6 and F41). For the detection of fimbrial antigens, the colonies of tested strains were cultured overnight on $7 \cdot 5 \%$ SBA (for F4 and F6 testing) and Minca agar (for F5 and F41 testing) and subjected to Staphylococcus aureus coagglutination using rabbit antisera specific for the different somatic and fimbrial antigens. An E. coli isolate was identified as an ETEC or putative ETEC strain if it possessed genes encoding specific colonizing fimbriae (F4, F5, F6 and F41) and/or enterotoxins (STa, STb and LT).

Statistical analysis. The statistical significance of differences in the incidence rates of diarrhoea and isolation of serogroups and pathotypes of ETEC were assessed between piggeries using the 
Chi-square test or Fisher's exact test with Yates' correction. All statistical significance was set at a (two-sided) $P$-value of $<0.05$ using the program GraphPad Instat version 3.01.

\section{RESULTS}

\section{Incidence of pre-weaning diarrhoea}

Over the 6 month study, 4986 piglets born alive from a total of 568 litters farrowed on the five CPs were investigated to determine the incidence of diarrhoea (Table 1). Of the 568 litters farrowed, diarrhoea was observed in 406 litters, i.e. a mean litter incidence rate of $71.5 \%$ for the 6 month period of study. The rates were higher in piggeries $\mathrm{A}, \mathrm{B}$ and $\mathrm{E}$ $(71 \cdot 5-79 \cdot 2 \%)$ than in piggeries $\mathrm{C}$ and $\mathrm{D}(63 \cdot 1-67 \cdot 9 \%)$. However, the difference was not significant $(P>0 \cdot 05)$. Of the 4986 piglets born alive, 3088 developed diarrhoea before the age of weaning $(61.9 \%)$. The incidence rate of individual piglets with diarrhoea was significantly higher $(P<$ $0 \cdot 001)$ in piggeries $\mathrm{A}$ and $\mathrm{B}(>60 \%)$ compared to the other piggeries.

\section{Prevalence of ETEC in piglets with diarrhoea}

A total of 406 specimens ( 372 faecal and 34 intestinal content specimens) were submitted from piglets with diarrhoea at the five CPs and examined for the presence of ETEC. A total of $200 \mathrm{E}$. coli isolates satisfied the selection criteria of heavy, pure or nearly pure growth on SBA and MCA $(49 \cdot 2 \%)$, of which 126 were subsequently identified as ETEC by PCR, accounting for $31 \%$ of the total number of specimens. ETEC were isolated from a total of $43 \%$ of cases of diarrhoea in piglets $1-4$ days of age and $23.9 \%$ of the remaining cases of diarrhoea up until the age of weaning.

A total of $62 \mathrm{E}$. coli isolates were obtained from specimens submitted to the NIVR diagnostic laboratory from VP sources during the same time period. Of these, 44 isolates $(71 \%)$ were confirmed as carrying at least one porcine ETEC virulence gene.

\section{Fimbrial and enterotoxin genes in ETEC isolates}

The prevalence of virulence factor genes among the 126 ETEC isolates from CPs is shown in Table 2. The majority of the isolates $(75 \cdot 4 \%)$ carried more than one enterotoxin gene. The STa gene $(92 \cdot 1 \%)$ was most common, followed by STb $(83 \cdot 3 \%)$ and LT $(55 \cdot 6 \%)$. Isolates containing STa or STb occurred either alone or in combination with each other and/or with LT. Isolates carrying the LT gene always possessed at least one additional enterotoxin gene. The most prevalent enterotoxin gene combination was $\mathrm{STa} / \mathrm{STb} / \mathrm{LT}$ $(55 \cdot 6 \%)$.

Fimbrial genes were detected in 88 isolates $(69 \cdot 8 \%)$, with F4 being the most common $(53 \cdot 1 \%)$, followed by F5 ( $16 \cdot 7 \%)$. Genes encoding F6, F41 and F18 fimbriae were not detected in any of the isolates examined. None of the isolates contained more than one fimbrial gene. The tested fimbrial genes were not identified in $30 \cdot 2 \%$ of isolates that were shown to possess at least one enterotoxin and these isolates were designated $\mathrm{F}-$. There was a close relationship between the possession of a fimbrial adhesin and different enterotoxin combinations. All isolates carrying the F4 fimbrial gene also possessed two or more enterotoxin genes $(\mathrm{STa} / \mathrm{STb}$ or $\mathrm{STa} / \mathrm{STb} / \mathrm{LT}$ ), while the F5 gene was frequently detected in combination with STa only. Isolates that were negative for all five tested fimbriae $(\mathrm{F}-)$ but still possessed one or more ETEC enterotoxins produced either STb only or all three in combination $(\mathrm{STa} / \mathrm{STb} / \mathrm{LT})$. Among the 126 ETEC isolates, five different pathotypes were recovered, with the most prevalent being $\mathrm{F} 4 / \mathrm{STa} / \mathrm{STb} / \mathrm{LT}$, accounting for $33 \cdot 3 \%$ of the isolates. Pathotype $\mathrm{F}-/ \mathrm{STb}$ had the lowest prevalence, occurring in only $7 \cdot 9 \%$ of the ETEC isolates. A large proportion of the isolates $(22.3 \%)$ belonged to the $\mathrm{F}-/ \mathrm{STa} /$ STb/LT pathotype.

The prevalence of virulence factor genes among VP isolates is also shown in Table 2. Isolates carrying F4 fimbriae and producing $\mathrm{STa} / \mathrm{STb} / \mathrm{LT}$ enterotoxins were most frequently detected $(45.5 \%)$, followed by F5-positive isolates that produced STa $(27 \cdot 3 \%)$. Isolates expressing STb only were the least common $(9 \cdot 1 \%)$. Four distinct pathotypes

Table 1. Results of a 6 month survey on pre-weaning piglet diarrhoea in five CPs ( $>100$ sows each) in north Vietnam

\begin{tabular}{|lcccc|}
\hline Piggery & $\begin{array}{c}\text { No. of } \\
\text { litters born }\end{array}$ & $\begin{array}{c}\text { No. of litters } \\
\text { with diarrhoea } \\
\text { (incidence rate) }\end{array}$ & $\begin{array}{c}\text { No. of } \\
\text { liveborne } \\
\text { piglets }\end{array}$ & $\begin{array}{r}\text { No. of piglets } \\
\text { with diarrhoea } \\
\text { (incidence rate) }\end{array}$ \\
\hline A & 96 & $76(79 \cdot 2)$ & 883 & $546(61 \cdot 8)^{*}$ \\
B & 249 & $36(67 \cdot 9)$ & 2291 & $1510(65 \cdot 9)^{*}$ \\
C & 53 & $53(63 \cdot 1)$ & 435 & $230(52 \cdot 9)$ \\
D & 84 & $63(73 \cdot 3)$ & 680 & $389(57 \cdot 2)$ \\
E & 86 & $406(71 \cdot 5)$ & 697 & $413(59 \cdot 3)$ \\
Total & 568 & 4986 & $3088(61 \cdot 9)$ \\
\hline
\end{tabular}

${ }^{\star} \mathrm{P}<0.001$ (compared amongst piggeries $\mathrm{A}, \mathrm{B}, \mathrm{C}, \mathrm{D}$ and $\mathrm{E}$ ) (two-tailed Chi-square test). 
Table 2. Fimbrial and enterotoxin genes detected in ETEC isolates of CP and VP origin

Data are presented as no. (\%).

\begin{tabular}{|c|c|c|c|c|c|c|}
\hline \multirow{2}{*}{$\begin{array}{l}\text { Origin of } \\
\text { isolate }\end{array}$} & \multirow{2}{*}{$\begin{array}{c}\text { Fimbrial } \\
\text { genes }\end{array}$} & \multicolumn{4}{|c|}{ Enterotoxin genes } & \multirow[t]{2}{*}{ Subtotal } \\
\hline & & STa & STb & $\mathrm{STa} / \mathrm{STb}$ & $\mathrm{STa} / \mathrm{STb} / \mathrm{LT}$ & \\
\hline \multirow{3}{*}{$\mathrm{CP}(n=126)$} & $\mathrm{F} 4$ & & & $25(19 \cdot 8)$ & $42(33 \cdot 3)$ & $67(53 \cdot 1)$ \\
\hline & F5 & $21(16 \cdot 7)$ & & & & $21(16 \cdot 7)$ \\
\hline & $\mathrm{F}-{ }^{*}$ & & $10(7 \cdot 9)$ & & $28(22 \cdot 3)$ & $38(30 \cdot 2)$ \\
\hline \multirow[t]{3}{*}{$\mathrm{VP}(n=44)$} & $\mathrm{F} 4$ & & & $8(18 \cdot 2)$ & $20(45 \cdot 5)$ & $28(63 \cdot 6)$ \\
\hline & F5 & $12(27 \cdot 3)$ & & & & $12(27 \cdot 3)$ \\
\hline & $\mathrm{F}-$ & & $4(9 \cdot 1)$ & & & $4(9 \cdot 1)$ \\
\hline
\end{tabular}

${ }^{*}$ Negative for F4, F5, F6, F41 and F18.

(F4/STa/STb/LT, F4/STa/STb, F5/STa and F-/STb) were found amongst the ETEC isolated from VPs, and all these pathotypes were also detected in $\mathrm{CP}$ isolates. Except for the $\mathrm{F}-/ \mathrm{STa} / \mathrm{STb} / \mathrm{LT}$ pathotype, which was detected in a high proportion of $\mathrm{CP}$ isolates but not in any of the VP isolates, no significant difference $(P>0 \cdot 05)$ in the prevalence of pathotypes was observed between $\mathrm{CP}$ and VP isolates.

\section{Relationships between piglet age groups and ETEC serogroups and pathotypes}

The distribution of ETEC isolates among different age groups of piglets in relation to serogroup, pathotype and the presence or absence of haemolysis is shown in Table 3. All isolates of the $\mathrm{F} 4 / \mathrm{STa} / \mathrm{STb} / \mathrm{LT}$ pathotype showed haemolysis on SBA and belonged to serogroup O149: K91, which was the predominant ETEC serogroup detected in all three age groups of piglets. Interestingly, the second most prevalent was found to be $\mathrm{F}-/ \mathrm{STa} / \mathrm{STb} / \mathrm{LT}$ isolates that belonged to serogroup O8. These isolates also were haemolytic and distributed in all age groups of piglets. All remaining isolates belonged to the other serogroups and were non-haemolytic.

O8:G7 isolates that belonged to pathotype $\mathrm{F} 4 / \mathrm{STa} / \mathrm{STb}$ were exclusively identified in the youngest age group of piglets (1-4 days of age). Serogroup O101 pathotype F4/ $\mathrm{STa} / \mathrm{STb}$ isolates were only identified in piglets $5-21$ days of age, but not in the immediate neonatal period. The serogroup O64 pathotype F5/STa strains were only isolated from piglets up to 14 days of age. None of the $\mathrm{F}-/ \mathrm{STb}$ isolates belonged to any of the tested $\mathrm{O}$ serogroups. However, among the non-typable isolates, seven still harboured the F4 gene

Table 3. Frequencies of $\mathrm{O}$ serogroups associated with pathotypes and haemolysis patterns in ETEC isolates

Data are presented as no. of ETEC isolates from CPs (no. of ETEC isolates from VPs). ONT, O nontypable with the ten $\mathrm{O}$ and $\mathrm{OK}$ antisera used.

\begin{tabular}{|c|c|c|c|c|c|c|c|c|}
\hline \multirow{2}{*}{$\begin{array}{l}\text { Age of piglets } \\
\text { (days) }\end{array}$} & \multirow{2}{*}{$\begin{array}{l}\text { Virulence } \\
\text { genes }\end{array}$} & \multirow{2}{*}{$\begin{array}{c}\text { No. of } \\
\text { haemolytic } \\
\text { isolates }\end{array}$} & \multicolumn{6}{|c|}{ O serogroup } \\
\hline & & & O149: K91 & O8: G7 & 08 & 064 & 0101 & ONT $^{*}$ \\
\hline \multirow[t]{5}{*}{$1-4(n=80)$} & $\mathrm{F} 4 / \mathrm{STa} / \mathrm{STb}$ & 14 & & 14 & & & & \\
\hline & $\mathrm{F} 4 / \mathrm{STa} / \mathrm{STb} / \mathrm{LT}$ & 30 & $18(12)$ & & & & & \\
\hline & $\mathrm{F} 5 / \mathrm{STa}$ & & & & & $13(6)$ & & (3) \\
\hline & $\mathrm{F}-/ \mathrm{STa} / \mathrm{STb} / \mathrm{LT}$ & 13 & & & 13 & & & \\
\hline & $\mathrm{F}-/ \mathrm{STb}$ & & & & & & & 1 \\
\hline \multirow[t]{5}{*}{$5-14(n=66)$} & $\mathrm{F} 4 / \mathrm{STa} / \mathrm{STb}$ & & & & & & $2(8)$ & 5 \\
\hline & $\mathrm{F} 4 / \mathrm{STa} / \mathrm{STb} / \mathrm{LT}$ & 23 & $15(8)$ & & & & & \\
\hline & $\mathrm{F} 5 / \mathrm{STa}$ & & & & & 8 & & (3) \\
\hline & $\mathrm{F}-/ \mathrm{STa} / \mathrm{STb} / \mathrm{LT}$ & 9 & & & 9 & & & \\
\hline & $\mathrm{F}-/ \mathrm{STb}$ & & & & & & & $4(4)$ \\
\hline \multirow[t]{4}{*}{$15-21 \quad(n=24)$} & $\mathrm{F} 4 / \mathrm{STa} / \mathrm{STb}$ & & & & & & 2 & 2 \\
\hline & $\mathrm{F} 4 / \mathrm{STa} / \mathrm{STb} / \mathrm{LT}$ & 9 & 9 & & & & & \\
\hline & $\mathrm{F}-/ \mathrm{STa} / \mathrm{STb} / \mathrm{LT}$ & 6 & & & 6 & & & \\
\hline & $\mathrm{F}-/ \mathrm{STb}$ & & & & & & & 5 \\
\hline
\end{tabular}


and six had the F5 gene together with one or more enterotoxin genes. Serogroups O8:G7 (pathotype F4/STa/STb) and $\mathrm{O} 8$ (pathotype $\mathrm{F}-/ \mathrm{STa} / \mathrm{STb} / \mathrm{LT}$ ) were exclusively associated with isolates from CPs and were detected on all five farms.

\section{DISCUSSION}

The rapid expansion of the Vietnamese pig industry from smallholder farms with less than 20 sows to larger, more intensive piggeries, has resulted in the cross-breeding of imported pig breeds with local breeds. Under such conditions, it is possible that unique ETEC serogroups and pathotypes that were present in indigenous breeds of pig may have been selected and become widely distributed in larger piggeries. The current study was therefore undertaken to determine the significance of ETEC as a cause of preweaning diarrhoea at five selected large CPs in north Vietnam and to compare ETEC serogroups and pathotypes between $\mathrm{CP}$ and VP sources.

Identifying the major ETEC serogroups and pathotypes responsible for pre-weaning diarrhoea in north Vietnam was the first step in implementing a management and control plan for ND based on vaccination of sows using endogenous strains. As expected, ETEC was a major factor in piglet diarrhoea, being isolated from $31.0 \%$ of cases. In a further $18.2 \%$ of cases, a heavy pure growth of E. coli was obtained, but subsequent molecular and/or serological investigation failed to identify any of the major ETEC virulence factors in these isolates. It is possible that these E. coli strains may possess other virulence factors that were not assayed for in the present study or that they are harmless commensals and were not involved in the aetiology of pre-weaning diarrhoea at the piggeries in question. The remaining $69 \%$ of cases of diarrhoea in the CPs that did not yield ETEC are likely to have been caused by other pathogens that are prevalent during the pre-weaning period in Vietnam. Transmissable gastroenteritis (TGE), rotavirus, coccidiosis and Clostridium perfringens have all recently been detected in CPs in north Vietnam (T. N. Do, S. J. Driesen and D. J. Trott, unpublished data).

Overall, 126 of 200 E. coli isolates obtained from CPs (63\%) and 44 of 62 isolates obtained from VPs $(71 \%)$ were identified as ETEC or putative ETEC, based on the detection of at least one virulence gene encoding enterotoxin (STa, $\mathrm{STb}$ and LT) and fimbriae (F4, F5, F6, F41 and F18). Interestingly, only F4 and F5 fimbriae were confirmed as being present in the isolates on the basis of both PCR and serology. In both CPs and VPs, F5 fimbriae were exclusively associated with ETEC isolates possessing STa, while the F4 gene displayed a greater variability in toxin gene association and was found with either STa/STb or STa/STb/LT. A total of seven distinct combinations of serogroup and pathotype were identified among ETEC isolates from CPs and four of these combinations were also present in ETEC isolates of VP origin. Interestingly, O8: G7 (F4/STa/STb), O8 (F-/STa/
$\mathrm{STb} / \mathrm{LT}$ ) and $\mathrm{O}$-non-typable isolates expressing $\mathrm{F} 4 / \mathrm{STa} / \mathrm{STb}$ were only detected in CPs.

Haemolytic serogroup O149: K91 isolates expressing the F4/ $\mathrm{STa} / \mathrm{STb} / \mathrm{LT}$ pathotype were the most frequently encountered ETEC in all three age groups of piglets $(33.3 \%$ of CP isolates and $45.5 \%$ of VP isolates). This may reflect the fact that at the time of sampling, prophylactic vaccination of sows for the passive transfer of protective maternal antibodies was not being practised in either production system, though both imported (F4/F5/F6/F41) and locally produced (F4 only) killed whole-cell bacterins had been in use in the $\mathrm{CPs}$ in the years preceding this study. The association between serogroup O149 and expression of the F4 antigen has been confirmed by many previous studies (Lund et al., 1982; Nagy et al., 1990, Harel, et al., 1991; Soderlind et al., 1988; Wilson \& Francis, 1986; Wittig \& Fabricius, 1992), and the isolates are usually haemolytic (Dam \& Knox, 1974; Soderlind, 1971; Soderlind \& Mollby, 1979; Wilson \& Francis, 1986; Wittig \& Fabricius, 1992). However, in earlier studies, O149 strains were only shown to produce LT, STa or STb alone, or, at most, LT/STa or LT/STb in combination (Harel et al., 1991; Soderlind \& Mollby, 1979; Wilson \& Francis, 1986). More recently, many O149 isolates have been shown to possess all three enterotoxins ( $\mathrm{STa}, \mathrm{STb}$ and $\mathrm{LT}$ ) (Fairbrother, 1999a; Frydendahl, 2002; Kwon et al., 1999; Noamani et al., 2003; Ojeniyi et al., 1994). Identification of ETEC that possess all three enterotoxins may indicate the emergence of a new and more virulent F4 ETEC pathotype (Fairbrother, 1999b).

The most noteworthy finding of this study was the relatively large number of ETEC isolates of $\mathrm{CP}$ origin (28 isolates, $22 \cdot 3 \%$ ) that belonged to serogroup O8, produced all three enterotoxins (STa, STb and LT) and did not possess any of the five recognized fimbriae $(\mathrm{F}-)$. This serogroup and pathotype was haemolytic, distributed in all age groups of pig in all five studied piggeries and was the second most prevalent behind serogroup O149: K91 strains that were F4 positive. Interestingly, the $\mathrm{F}-/ \mathrm{STa} / \mathrm{STb} / \mathrm{LT}$ pathotype was not present in any isolates from VPs. The large number of $\mathrm{F}-/ \mathrm{STa} / \mathrm{STb} / \mathrm{LT}$ isolates could reflect the previous use of ETEC whole-cell bacterins containing F4 alone or in combination with the other fimbrial types associated with ND in the CPs. This would also explain the absence of the F-/STa/ $\mathrm{STb} / \mathrm{LT}$ pathotype in isolates from VPs raised by smallholding farmers, who do not regularly use vaccines for the control of ETEC infection, although it is possible that the $\mathrm{F}-/ \mathrm{STa} /$ $\mathrm{STb} / \mathrm{LT}$ may have been detected in VPs if more isolates had been examined. It also is conceivable that the $\mathrm{F}-$ strains may have been present in the gastrointestinal tract of pigs imported into Vietnam. However, this unique pathotype has not been reported in Australia (Driesen et al., 1993), which exported live pigs to Vietnam, or in any other pigproducing country.

Although vaccination has been suggested to result in shifts in fimbrial antigens associated with ETEC in pigs (Garabal et al., 1997; Guinee \& Jansen, 1979; Moon \& Bunn, 1993; 
Soderlind et al., 1982, 1988), these have been minor and short-lived, and despite extensive vaccination with F4ac vaccines in the USA and Europe this antigenic type remains dominant among ETEC implicated in diarrhoea in most countries (Moon, 1990; Westerman et al., 1988; Wittig \& Fabricius, 1992; Moon \& Bunn, 1993), as well as in the present study. The high proportion of O8 isolates expressing $\mathrm{F}-/ \mathrm{STa} / \mathrm{STb} / \mathrm{LT}$ could in part explain the apparent failure of previous prophylactic vaccination programmes in CPs in Vietnam. However, as ETEC were only found to be responsible for $31 \%$ of cases, this may not be as significant as the influence of other causes of pre-weaning diarrhoea in older age groups of piglets such as TGE, rotavirus and coccidiosis. Other factors, such as inappropriate sow, gilt and piglet management during farrowing and early lactation, may also contribute to the high incidence of diarrhoea in suckling pigs in Vietnam.

The $\mathrm{O} 8(\mathrm{~F}-/ \mathrm{STa} / \mathrm{STb} / \mathrm{LT})$ and $\mathrm{O} 149(\mathrm{~F} 4 / \mathrm{STa} / \mathrm{STb} / \mathrm{LT})$ strains were both haemolytic and isolated from all age groups of piglets at each of the five CPs. Similar strains that lack recognized fimbriae belonging to $\mathrm{O} 8$ and additional serogroups, including O101, O139, O138, O141, O147, O149 and O157, have been noted in studies from other countries, including Japan (Nakazawa et al., 1987), Sweden (Soderlind et al., 1988) and Denmark (Ojeniyi et al., 1994). However, it is unusual to find the production of LT enterotoxin associated with strains other than F4- or F18-positive ETEC (Harel et al., 1991; Ojeniyi et al., 1994; Wilson \& Francis, 1986), with a few notable exceptions (Broes et al., 1988; Lund et al., 1982). This makes the O8 strains identified in the present study even more unusual in that they possess LT in association with STa and STb enterotoxins. This strongly suggests that unlike the non-typable isolates that were only shown to carry $\mathrm{STb}$, the $\mathrm{O} 8$ isolates are very likely to be pathogenic and could possess an as yet undetermined novel colonization factor. In support of this hypothesis, the $\mathrm{O} 8(\mathrm{~F}-/ \mathrm{STa} / \mathrm{STb} / \mathrm{LT})$ strains possessed a unique mannoseresistant haemagglutination property, were shown by electron microscopy to express fimbriae and were capable of attachment in vitro to isolated porcine brush borders. In addition, a representative isolate caused hypersecretory diarrhoea and was only found to be attached to the ileum of challengeexposed, colostrum-deprived 1-day-old piglets (Do et al., 2006).

The presence of serogroup O7/O157 strains expressing a new adherence factor (AIDA-I) in combination with other ETEC virulence genes (AIDA/STb/EAST1 or AIDA/STb) has been confirmed in piglets with diarrhoea in Canada. This prompted the suggestion that AIDA-I plays a possible role in the pathogenesis of ETEC-associated diarrhoea in piglets (Ngeleka et al., 2003). The relatively high frequency of $\mathrm{O} 8(\mathrm{~F}-/ \mathrm{STa} / \mathrm{STb} / \mathrm{LT})$ strains in CPs in north Vietnam together with their confirmed pathogenic potential in 1day-old piglets provides an incentive for further studies to investigate their origin and the genetic basis of attachment. Furthermore, the inclusion of these unusual strains in ETEC vaccines together with the other common F4 and F5 pathotypes in Vietnam may confer better protection to piglets against ETEC infection during the pre-weaning period.

\section{ACKNOWLEDGEMENTS}

Do Ngoc Thuy was the recipient of an Australian Center for International Agricultural Research John Allright Fellowship. The authors gratefully acknowledge the technical assistance of Brenda McCormick (serology) and Ross Bowles (PCR) and the assistance of the manager and workers at each participating piggery in north Vietnam.

\section{REFERENCES}

Bertschinger, H. U. \& Fairbrother, J. M. (1999). Escherichia coli infections. In Diseases of Swine, pp. 431-468. Edited by B. E. Straw, S. D’Allaire, W. L. Mengeling \& D. J. Taylor. Ames, Iowa: Iowa State University Press.

Blanco, M., Blanco, J. E., Gonzalez, E. A. \& 7 other authors (1997). Genes coding for enterotoxins and verotoxins in porcine Escherichia coli strains belonging to different $\mathrm{O}: \mathrm{K}: \mathrm{H}$ serotypes: relationship with toxigenic phenotypes. J Clin Microbiol 35, 2958-2963.

Broes, A., Fairbrother, J. M., Lariviere, S., Jacques, M. \& Johnson, W. M. (1988). Virulence properties of enterotoxigenic Escherichia coli O8: KX105 strains isolated from diarrheic piglets. Infect Immun 56, 241-246.

Cu, H. P., Vu, B. M., Nguyen, N. N. \& Do, N. T. (1999). Isolation and identification of biochemical characteristics of E. coli and Salmonella from piglets with diarrhoea. Prevention measures. In The Veterinary Scientific Congress. Edited by NIVR. Hanoi, Vietnam: National Institute of Veterinary Research.

Dam, A. \& Knox, B. (1974). Haemolytic Escherichia coli associated with enteritis and enterotoxaemia in pigs in Denmark, with particular reference to the rapid spread of serogroup O149:K91. Nord Vet Med 26, 219-225.

Do, T., Stephens, C., Townsend, K., Wu, X., Chapman, T., Chin, J., McCormick, B., Bara, M. \& Trott, D. J. (2005). Rapid identification of virulence genes in enterotoxigenic Escherichia coli isolates associated with diarrhoea in Queensland piggeries. Aust Vet J 83, 293-299.

Do, T. N., Wilkie, I., Driesen, S. J., Fahy, V. A. \& Trott, D. J. (2006). Pathogenicity of Vietnamese enterotoxigenic Escherichia coli strains in colostrum deprived one-day-old pigs. Vet Pathol (in press).

Driesen, S. J., Carland, P. G. \& Fahy, V. A. (1993). Studies on preweaning piglet diarrhoea. Aust Vet J 70, 259-262.

Fairbrother, J. M. (1999a). Neonatal Escherichia coli diarrhoea. In Diseases of Swine, pp. 433-441. Ames, Iowa: Iowa State University Press.

Fairbrother, J. M. (1999b). Identification, nomenclature, and diagnosis of pathogenic E. coli. In Proceedings of the Annual Meeting of the Western Canadian Association of Swine Practitioners, pp. 21-31. Saskatoon, Saskatchewan.

Frydendahl, K. (2002). Prevalence of serogroups and virulence genes in Escherichia coli associated with postweaning diarrhhoea and edema disease in pigs and a comparison of diagnostic approaches. Vet Microbiol 85, 169-182.

Garabal, J. I., Vazquez, F., Blanco, J., Blanco, M. \& Gonzalez, E. A. (1997). Colonization antigens of enterotoxigenic Escherichia coli strains isolated from piglets in Spain. Vet Microbiol 54, 321-328.

Guinee, P. A. M. \& Jansen, W. H. (1979). Behavior of Escherichia coli $\mathrm{K}$ antigens K88ab, K88ac, and K88ad in immunoelectrophoresis, double diffusion, and haemagglutination. Infect Immun 23, 700-705. 
Harel, J., Lapointe, H., Fallara, A., Lortie, L. A., Bigras-Poulin, M., Lariviere, S. \& Fairbrother, J. M. (1991). Detection of genes for fimbrial antigens and enterotoxins associated with Escherichia coli serogroups isolated from pigs with diarrhoea. J Clin Microbiol 29, 745-752.

Hoang, K. G. (2003). The Current Situation of Livestock Production and Waste Management in Vietnam. Hanoi, Vietnam: Department of Agriculture and Forestry Extension, Ministry of Agriculture and Rural Development.

Kwon, D., Kim, O. \& Chae, C. (1999). Prevalence of genotypes for fimbriae and enterotoxins and of $\mathrm{O}$ serogroups in Escherichia coli isolated from diarrheic piglets in Korea. J Vet Diagn Invest 11, 146-151.

Lund, A., Fossum, K. \& Liven, E. (1982). Serological, enterotoxinproducing and biochemical properties of Escherichia coli from piglets with neonatal diarrhoea in Norway. Acta Vet Scand 23, 79-87.

Moon, H. W. (1990). Colonization factor antigens of enterotoxigenic Escherichia coli in animals. Curr Top Microbiol Immunol 151, 147-165.

Moon, H. W. \& Bunn, T. O. (1993). Vaccines for preventing enterotoxigenic Escherichia coli infections in farm animals. Vaccine 11, 213-220.

Nagy, B. \& Fekete, P. Z. (1999). Enterotoxigenic Escherichia coli (ETEC) in farm animals. Vet Res 30, 259-284.

Nagy, B., Casey, T. A. \& Moon, H. W. (1990). Phenotype and genotype of Escherichia coli isolated from pigs with postweaning diarrhoea in Hungary. J Clin Microbiol 28, 651-653.

Nakazawa, M., Sugimoto, C., Isayama, Y. \& Kashiwazaki, M. (1987). Virulence factors in Escherichia coli isolated from piglets with neonatal and post-weaning diarrhoea in Japan. Vet Microbiol 13, 291-300.

Nataro, J. P. \& Kaper, J. B. (1998). Diarrheagenic Escherichia coli. Clin Microbiol Rev 11, 142-201.

Ngeleka, M., Pritchard, J., Appleyard, G., Middleton, D. M. \& Fairbrother, J. M. (2003). Isolation and association of Escherichia coli AIDA-I/STb, rather than EAST1 pathotype, with diarrhea in piglets and antibiotic sensitivity of isolates. J Vet Diagn Invest 15, 242-252.

Nguyen, T. D. (1995). Animal health improvement: a high priority for livestock development. In Exploring Approaches to Research in the
Animal Sciences in Vietnam, pp. 57-62. Edited by W. J. Pryor. Hue, Vietnam: ACIAR Proceedings.

Noamani, B. N., Fairbrother, J. M. \& Gyles, C. L. (2003). Virulence genes of O149 enterotoxigenic Escherichia coli from outbreaks of postweaning diarrhea in pigs. Vet Microbiol 97, 87-101.

Ojeniyi, B., Ahrens, P. \& Meyling, A. (1994). Detection of fimbrial and toxin genes in Escherichia coli and their prevalence in piglets with diarrhoea. The application of colony hybridization assays, polymerase chain reaction and phenotypic assays. Zentralbl Veterinarmed B 41, 49-59.

Osek, J. (1999). Prevalence of virulence factors of Escherichia coli strains isolated from diarrheic and healthy piglets after weaning. Vet Microbiol 68, 209-217.

Osek, J., Gallien, P., Truszczynski, M. \& Protz, D. (1999). The use of polymerase chain reaction for determination of virulence factors of Escherichia coli strains from pigs in Poland. Comp Immunol Microbiol Infect Dis 22, 163-174.

Soderlind, O. (1971). Studies on Escherichia coli in pigs. I. Biochemical investigations. Zentralbl Veterinarmed B 18, 489-504.

Soderlind, O. \& Mollby, R. (1979). Enterotoxins, O-groups, and K88 antigen in Escherichia coli from neonatal piglets with and without diarrhea. Infect Immun 24, 611-616.

Soderlind, O., Olsson, E., Smyth, C. J. \& Mollby, R. (1982). Effect of parenteral vaccination of dams on intestinal Escherichia coli in piglets with diarrhea. Infect Immun 36, 900-906.

Soderlind, O., Thafvelin, B. \& Mollby, R. (1988). Virulence factors in Escherichia coli strains isolated from Swedish piglets with diarrhoea. J Clin Microbiol 26, 879-884.

Trinh, V. T. (1980). Swine Diseases in Vietnam. Hanoi, Vietnam: The Sciences and Techniques Publishing House (in Vietnamese).

Westerman, R. B., Mills, K. W., Phillips, R. M., Fortner, G. W. \& Greenwood, J. M. (1988). Predominance of the ac variant in K88-positive Escherichia coli isolates from swine. J Clin Microbiol 26, 149-150.

Wilson, R. A. \& Francis, D. H. (1986). Fimbriae and enterotoxins associated with Escherichia coli serogroups isolated from pigs with colibacillosis. Am J Vet Res 47, 213-217.

Wittig, W. \& Fabricius, C. (1992). Escherichia coli types isolated from porcine E. coli infections in Saxony from 1963 to 1990. Zentralbl Bakteriol 277, 389-402. 